Rabaska

Revue d'ethnologie de l'Amérique française

\title{
L'interprétation du patrimoine dans les provinces de l'Atlantique : un regard croisé entre la théorie et la pratique
}

\section{Ronald Labelle}

Volume 18, 2020

URI : https://id.erudit.org/iderudit/1072918ar

DOI : https://doi.org/10.7202/1072918ar

Aller au sommaire du numéro

Éditeur(s)

Société québécoise d'ethnologie

ISSN

1703-7433 (imprimé)

1916-7350 (numérique)

Découvrir la revue

Citer ce document

Labelle, R. (2020). L'interprétation du patrimoine dans les provinces de l'Atlantique : un regard croisé entre la théorie et la pratique. Rabaska, 18, 271-274. https://doi.org/10.7202/1072918ar d'utilisation que vous pouvez consulter en ligne. 


\title{
Colloques et rassemblements
}

\section{L'interprétation du patrimoine dans les provinces de l'Atlantique : un regard croisé entre la théorie et la pratique}

\author{
RonALD LABELLE \\ Cape Breton University
}

En septembre 2019, l'Université du Cap-Breton était l'hôte d'un colloque d'envergure nationale intitulé « L'interprétation du patrimoine dans les provinces de l'Atlantique : un regard croisé entre la théorie et la pratique ». Cet événement de nature bilingue rassemblait une cinquantaine d'universitaires et de praticiens du secteur public engagés dans l'étude et l'interprétation du patrimoine immatériel. Alors que le patrimoine culturel immatériel, ou $\mathrm{PCI}_{\mathrm{C}}$, est aujourd'hui un concept bien reconnu dans nos provinces voisines du Québec et de Terre-Neuve-et-Labrador, où les politiques culturelles reflètent désormais son importance, les provinces Maritimes accusent un retard dans ce domaine et les organisateurs espéraient ainsi sensibiliser les participants à la question.

Ce colloque, organisé par les ethnologues Gerald Pocius et Ronald Labelle, visait à amener les participants à reconnaître l'importance du patrimoine immatériel dans nos communautés. Gerald Pocius, professeur émérite à Memorial University de Terre-Neuve, a acquis une longue expérience en tant que promoteur du $\mathrm{P}_{\mathrm{CI}}$ au sein de la Commission canadienne pour l'UNESCO, alors que Ronald Labelle a été spécialiste de la culture orale acadienne pendant une carrière s'échelonnant sur une quarantaine d'années. Plutôt que de se limiter à un groupe de chercheurs universitaires, les organisateurs ont lancé l'invitation à toutes les personnes impliquées dans l'interprétation du patrimoine culturel en Atlantique, que ce soit dans des musées et centres de documentation, des organismes culturels, des lieux historiques ou ailleurs.

En mettant en parallèle deux perspectives différentes, celle des théoriciens du patrimoine et celle des personnes œuvrant sur le terrain, le colloque favorisait donc un échange de points de vue, que ce soit par la tenue de communications individuelles, de séances, d'ateliers ou de tables rondes. 
Les organisateurs espéraient ainsi encourager de nouvelles initiatives qui refléteraient un équilibre entre les besoins économiques des communautés de la région et le besoin d'assurer l'authenticité dans la représentation de la culture.

L'Université du Cap-Breton semblait l'endroit idéal pour la tenue du colloque. Il s'agit en effet de la seule université des Maritimes où le folklore et l'ethnologie sont non seulement présents comme domaine d'enseignement, mais occupent aussi une place de choix aux archives du Beaton Institute for Cape Breton Studies, ainsi qu'au Centre for Cape Breton Studies, qui comprend un studio d'enregistrement sonore dédié à la musique traditionnelle du Cap-Breton. Mentionnons aussi qu'une des constituantes de l'Université du Cap-Breton est Unama'ki College, un lieu de formation et de recherche en Études autochtones.

Le colloque a réuni des participants de partout en Atlantique, auxquels s'ajoutaient quelques invités de l'extérieur, tel que Laurier Turgeon, titulaire de la Chaire de recherche du Canada en patrimoine ethnologique à l'Université Laval. Le tout a débuté le 13 septembre par une conférence inaugurale prononcée par Henry Glassie, chercheur de renommée internationale. Henry Glassie, professeur émérite à Indiana University, est un des plus importants spécialistes de la culture matérielle traditionnelle. Sa conférence, inspirée de ses expériences en recherche sur cinq continents, a donné le ton au colloque, démontrant les liens serrés qui existent entre la culture matérielle et immatérielle, qu'il s'agisse du tissage de tapis en Turquie ou de la construction de toits de chaume en Irlande.

Un des buts du colloque était de mettre en vitrine la diversité culturelle des Maritimes et, en particulier, du Cap-Breton. C'est ainsi qu'une place importante a été accordée à la culture d'expression gaélique, ainsi qu'aux communautés autochtones. Les participants se sont déplacés pendant la première journée, visitant le Membertou Heritage Park, lieu d'interprétation de la culture Mi'kmaq, et aussi le Highland Village (Baile nan Gaidheal) situé à Iona. En plus d'être peuplé de Mi'kmaq, d'Écossais, d'Irlandais et d'Acadiens, le Cap-Breton a aussi été une terre d'accueil pour des immigrants de l'Europe et des Antilles, venus pour travailler dans les industries de la région. Afin de souligner cette présence, les participants ont été invités à prendre part à un souper et à une soirée culturelle polonaise au Polish Village Hall de Sydney. Il vaut la peine de signaler que cette soirée a eu lieu en présence de l'Ambassadeur de Pologne au Canada.

Dans son ensemble, le colloque a permis aux participants de constater qu'il existe dans la région de l'Atlantique (y compris les Îles-de-la-Madeleine) une étonnante richesse culturelle qu'un grand nombre d'organismes patrimoniaux tentent de préserver et de promouvoir, souvent avec peu de 
ressources. Parmi les thèmes mis de l'avant lors de ce colloque, mentionnons "Les sources numériques et médiatiques en tant que moyens de diffusion », « Le PCI à Terre-Neuve-et-Labrador », « La préservation du patrimoine et la transmission du savoir ", " Le patrimoine oral en Acadie », « Le monde muséal en évolution » et «Les lieux de mémoire».

Pour beaucoup de participants, il s'agissait d'une première prise de contact avec des gens qui œuvrent à des projets semblables aux leurs dans d'autres régions. C'est ainsi, par exemple, que les responsables du « Projet culturel les Héritiers » aux Îles-de-la-Madeleine ont pu échanger avec Dale Jarvis, le directeur de « Living Heritage Newfoundland and Labrador », un organisme créé par le gouvernement provincial de cette province. Plusieurs participants ont présenté des lieux d'interprétation de la culture traditionnelle acadienne, qu'il s'agisse du «Centre de la Mi-carême » situé à Saint-Josephdu-Moine au Cap-Breton, de la maison « Chez Deslauriers » de Pomquet, Nouvelle-Écosse, ou des musées acadiens de l'Île-du-Prince-Édouard et de l'Université de Moncton. Un autre exposé qui mérite d'être signalé est celui du spécialiste d'architecture traditionnelle Robert Mellin, qui comparait les modes de préservation du patrimoine retrouvés dans deux villages à caractère touristique, Peggy's Cove, Nouvelle-Écosse, et Tilting sur l'île de Fogo à Terre-Neuve.

Afin de donner le ton aux discussions en groupes qui clôturaient le colloque, quatre spécialistes ont présenté une table ronde examinant la position du Canada vis-à-vis la Convention de l'UnESCO sur la sauvegarde du patrimoine culturel immatériel. Ce groupe comprenait Gerald Pocius, Laurier Turgeon, Dale Jarvis et enfin Stephen Augustine, chef héréditaire Mi'kmaq et dirigeant du Unama'ki College. Tout en déplorant le fait que le Canada est un des rares pays qui refuse toujours de signer la convention de l'UNESCO, à laquelle 182 des 195 pays membres de l'organisation adhèrent déjà, les conférenciers ont signalé que quelques provinces, dont le Québec, Terre-Neuve-et-Labrador et la Saskatchewan, ont déjà mis en œuvre des activités qui s'inscrivent dans l'esprit de la Convention.

Une discussion animée a eu lieu le dernier jour du colloque. Les participants ont alors réfléchi ensemble sur les meilleures pratiques à adopter pour promouvoir le PCI. Ils ont reconnu que le $\mathrm{P}_{\mathrm{CI}}$ est enraciné partout dans nos communautés et que les organismes communautaires doivent donc être impliqués dans l'étude et la sauvegarde du patrimoine immatériel. Ils ont aussi reconnu que les individus et organismes œuvrant dans le domaine pourraient grandement bénéficier d'échange et de transfert de l'expertise déjà acquise à divers endroits.

Lors des ateliers tenus à la fin du colloque, on a aussi exprimé le souhait que le matériel et les documents élaborés par l'UNESCO pour la mise en œuvre 
de la Convention sur le patrimoine immatériel soient mis à la disposition de tous les intervenants dans le domaine. Ces instruments couvrent, par exemple, les connaissances nécessaires à l'élaboration de plans de sauvegarde. Une difficulté se pose toutefois, car toute la programmation de l'UNESCO en matière de PCI s'adresse soit aux États membres de la Convention ou à ceux qui sont en voie de le devenir. Or, comme on le sait, le Canada se tient toujours à l'écart du processus et ne s'est pas encore montré prêt à corriger cette lacune.

Les participants ont reconnu le besoin de créer un réseau de chercheurs et de praticiens en PCI, afin que le travail entrepris pendant ces trois jours de rencontres se poursuive. L'état fragmentaire des activités patrimoniales dans les provinces de l'Atlantique rend difficile la réalisation de ce souhait, mais il existe déjà un réseau informel de communication par le biais d'un groupe Facebook intitulé Atlantic Canada Heritage Professionals. Enfin, les nombreux participants venus des quatre coins de la Nouvelle-Écosse se sont quittés en souhaitant que cette province se dote enfin d'un Conseil du patrimoine semblable à ce qui existe à d'autres endroits comme au Québec. 